\title{
The Increasing Quest for Instructional Designers and Technologists in Higher Education and Corporate Settings
}

\author{
John Nworie \\ Independent Researcher, USA \\ ORCID: 0000-0002-4602-7511
}

Received: 17 Jun 2021

Accepted: 26 Sep 2021

\begin{abstract}
As recognition of the roles and contributions of Instructional Design and Technology (IDT) professionals has increased, so has the demand for their skills in the workplace whether in higher education institutions or business entities. However, there remains some ambiguity, especially in higher education, about who IDTs are and what they do. There are also questions about who is hiring them. This content analysis study of 250 advertised higher education and corporate IDT positions found no fewer than 9 job titles, 13 academic programs, 5 degree levels, work experience from 1 to 10 years, and compensation that ranged from an hourly pay to a six-digit annual salary. Required skillsets included not only technical and analytical expertise but personal qualities. This study was conducted to provide a current look at the employment opportunities for Instructional Designers and Instructional Technologists.
\end{abstract}

Keywords: higher education, IDT employment, IDT graduates, careers in instructional design and technology, IDT roles and responsibilities, IDT programs, instructional design, instructional technology

\section{INTRODUCTION}

The IDT field has continued to grow and so has the demand for IDTs in various work contexts, prompting this study to look at the hiring trends in higher education and corporate settings based on the content analysis of position announcements for instructional designers and instructional technologists. The increased need for support in training, performance improvement, online learning, integration of technology into instruction, and the application of appropriate pedagogy continue to fuel the growth of active learning approaches (Kumar \& Ritzhaupt, 2017) and the demand for the professionals who support the teaching and learning process. As the field has continued to evolve, so has the increase in the roles and responsibilities of IDTs, as well as the requirements by prospective employers. The increasing need to provide efficient instructional interventions to improve employee performance as well as the quality of their services or products in business, industry, government, military, and healthcare, and the need to improve teaching and learning in online and classroom environments in educational organizations, calls for IDTs with commensurate skills and abilities (Raynis, 2018). The need has been further boosted by developments in learning theories, instructional design models, emerging technologies, growing interest in online learning, and advancements in communication technologies, all of which multiply the diversity of instructional delivery methods. These developments further call for new and enhanced skills and competencies of IDTs (Moallem, 1995).

Intentional Futures (2016) reported 13,000 instructional design professionals working in US colleges and universities. That number is expected to continue to grow in coming years. IDTs play different roles in their work settings and assume such functions as instructional designers, educational/instructional technologists, curriculum designers, course developers, multimedia producers, unit managers, trainers, and more. The 
literature documents that IDTs varied skill sets are not stagnant. Their knowledge base includes instructional design models and processes, project management, learning theories, pedagogy, multimedia, and technology skills (Ritzhaupt \& Kumar, 2015). The roles of IDTs are not restricted to integrating technology and instruction, applying instructional design models, utilization of learning theories, or engaging in course improvement efforts. Other endeavors they engage in include serving on committees, taking up the role of project managers, researching and deploying new technologies and innovations, serving as unit heads, managing budgets, managing schedules, supporting faculty, conducting workshops, and managing professional development events (Kenny et al., 2005).

There is the awareness in higher education of the importance of preparing and supporting faculty in the process of course improvement, integration of technology and pedagogy, and the application of instructional design (Bickerstaff \& Cormier, 2015; Chiasson et al., 2015; Elliott et al., 2015). Irlbeck (2011) recognizes IDT as an evolving profession that welcomes some degree of technology expertise, an understanding of the instructional design process, a capacity to communicate, and strong problem-solving skills.

Because of the different preferences and requirements by prospective employers, contextual considerations are encouraged in the preparation and description of roles and clarity on positions for different specific industries (Larson \& Lockee, 2009; Sugar et al., 2011; Raynis, 2018). According to Sugar et al. (2011), "the organizational culture within a corporation is radically different than that which is found within a college or university setting" (p. 30). As IDTs are expected to have a plethora of skills to function in their roles, those joining the field are equally expected to demonstrate a variety of competencies if they are to be successful in the field (Ritzhaupt \& Martin, 2014).

Higher education has embraced instructional technology as a means of supporting instruction in conventional classroom settings and in delivering online instruction to geographically dispersed learners. This phenomenon has contributed to the increased quest for instructional designers and instructional technologists in higher education. IDTs are considered as specialists who can integrate computer technology with appropriate pedagogies in the delivery of instruction in multiple modalities including online learning, hybrid courses, assessment of student learning, and improved face-to-face instruction. Business, industry, and the military have also found value in the employment of IDTs to create training programs (Raynis, 2018).

Technological innovations introduced in the early 21 st century have redefined directions in distance learning and classroom instruction (Sharif \& Cho, 2015) and led to the demand for IDTs to support faculty and subject matter experts in the process of improving classroom instruction and turning face-to-face instruction into online courses. The range of their involvement includes development of instructional multimedia; support in the use of electronic grade books, clickers, and course captures; introduction to learning management systems and student learning assessments; and even broader endeavors such as deployment of massive online courses and design of learning spaces. In these various roles, IDTs collaborate with faculty to advance the learning experience of undergraduate students, returning adult learners, and those learning at a distance.

In 2001, Surry and Robinson documented an increase in the demand for instructional designers, instructional technologists, course and curriculum specialists, and a variety of supporting administrative positions. Since that report, there has been a continued and consistent search for professionals in this field. A search of jobposting sites, depending on the specific search terms, will yield hundreds or thousands of position announcements for IDTs and related opportunities such as learning experience designers, instructional developers, learning system designers, and educational technologists.

\section{Instructional Design and Instructional Technology}

Ongoing discussions have failed to reach a consensus about how to correctly refer to the instructional designers and instructional technologists in the field and how to refer to the academic programs that prepare them. In position announcements and in work settings, the instructional designers and instructional technologists are also identified by different titles. The study by Raynis (2018) identified different titles that are used for IDTs. The words "Instructional" and "Designer" were found in $78.5 \%$ and $83.9 \%$, respectively, of the job titles. 
As an academic field, "instructional design" has had a long history. While "instructional design" is the most popular term presently used to refer to the field and the instructional design and instructional technology (IDT) practitioners, some ideas have emerged urging a change of name (Da Silva, 2016; Kilgore, 2016; Malamed, 2015). One suggested new term is "Learning Experience Design," which is often shortened to "LX design." One of the arguments for this name change is that it "describes and encompasses current trends in instructional design" (Kilgore, 2016). The titles of IDTs in their different work settings could suggest subtle differences in their job roles, since different work experiences call on different IDT competencies (Hoard et al., 2019) as well as their roles and titles.

In the process of their study titled "A Taxonomy of Instructional Technology Service Positions in Higher Education," Surry and Robinson (2001), found that no consistency existed in the title for IDTs. They then proceeded to categorize the titles based on the stated responsibilities of the positions. In their report, they noted that by doing so they were able to distinguish between an Instructional Technologist and Instructional Designer. They concluded that an Instructional Technologist "helps faculty learn about technology, become proficient with technology, and integrate technology into their teaching," while Instructional Designers engage in wider responsibilities that includes "leading the development of specific instructional products."

Many instructional designers and instructional technologists are often the graduates of the same IDT academic programs and share the same knowledge base but will inevitably wind up working in different settings and performing different roles. Because those roles are often comparable, both practice areas are often listed in job announcements titles as instructional designers, instructional technologists, learning designers, instructional developers, and instructional systems designers, among others.

Individuals with degrees from academic programs outside of IDT or with related on-the-job training or experience are known to have been employed as instructional designers or technologists, in which case the job title may be unique to the employing organization rather than that associated with their academic training or competencies. Beirne and Romanoski (2018) explored the reasons for a growing demand for IDTs and noted that people enter the profession from different fields. The knowledge that there are multiple unregulated paths to a career as an IDT professional led the authors to suggest the need for standardization in the entry into the profession.

The continuing interest and increase in the employment of IDTs prompted this study to document the advertised job titles, the academic and work experience requirements of candidates, the work settings, the skills employers are seeking, and available information on compensation. This will help to create an understanding of the current job market and allay any lingering doubts about the role of IDTs in higher education and other settings (Intentional Futures, 2016).

While there have been previous job announcement analyses focusing on the roles, competencies, places of employment, preparation of IDTs, and experience of IDTs, this study follows along the tradition by investigating the increase in the hiring of IDTs, exploring the competencies sought, and the background of the IDTs. Engaging frequently in studies such as this is essential as the field is constantly evolving, the required skills are increasing, processes employed are changing, and new technologies are being introduced. The continuous analysis of the job announcements could shed more light on new competencies and identify previous work experience required of applicants. The findings can benefit prospective graduates, academic programs, and IDT professionals in the field.

For the purposes of this study, IDT(s) will be used as inclusive terms for Instructional Designers and Instructional Technology practitioners and programs.

\section{LITERATURE REVIEW}

The professional field of IDT can be regarded as constantly evolving, dynamic, and complex as it is concerned with different learning theories, emerging pedagogy, rapid developments in technology, a variety of instructional delivery methods, a plethora of instructional design models, diverse learner characteristics, and different demands in a wide array of work environments. The complexities and evolutionary nature of the 
field often poses a challenge to IDT faculty about how to prepare their students on the requisite competencies to enable them find employment, and professionals in the field on how to keep abreast of developments to remain relevant in the field or to advance in their career. However, there are resources that help to mitigate the challenges in the preparation provided by academic IDT programs, professional development opportunities offered by professional associations (Ritzhaupt et al., 2020), and researchers have consistently explored the changing roles and responsibilities and evaluated the skills and competencies that are essential for practitioners. The need to continually examine the competencies of IDT professionals is predicated on the expectations of prospective employers (Wang et al., 2021).

Studies have been conducted on the competencies and roles of IDT professionals in the past several years (Daniels et al., 2012; Ritzhaupt \& Kumar, 2015; Ritzhaupt \& Martin, 2014; Ritzhaupt et al., 2020; Ritzhaupt, Martin et al., 2018; Rowland, 1992). Some of the studies focused on competencies associated with different work settings such as higher education, corporate, government, K-12, and healthcare (Christensen \& Osguthorpe, 2004; Cox \& Osguthorpe, 2003; Kenny et al., 2005; Kumar \& Ritzhaupt, 2017; Litchfield, 2017; Raynis, 2018; Ritzhaupt \& Kumar, 2015). Other studies focused on the challenges, constraints, and contextual issues that IDTs face in their places of employment (Gray et al., 2015; Hoard et al., 2017; Stefaniak et al., 2018). Extant research studies conducted to identify IDT roles and competencies have applied different methodologies. A content analysis methodology analyzed the job announcements from various job posting sources (Kang \& Ritzhaupt, 2015; Moallem, 1995; Raynis, 2018; Ritzhaupt et al., 2010; Sugar et al. 2012; Wang et al., 2021). Other methodologies used include in-depth interviews, the Delphi method, survey-based research, and mixed method (Irby \& Strong, 2015; Kang \& Ritzhaupt, 2015; Klein \& Kelly, 2018; Ritzhaupt et al., 2010, 2018; Ritzhaupt \& Kumar, 2015; Rozitis, 2017; Sugar et al., 2007; Williams van Rooij, 2013).

This diversity of methodologies has enabled researchers approach the identification of the competencies of IDT professionals from multiple angles and document different viewpoints.

In comparing the different research approaches used to examine the roles and competencies of IDTs, content analysis is frequently used in job announcement analysis and seems to be the best approach to identifying the most sought professional competencies in wide-ranging fields (Wang et al., 2021). Wang et al. further assert that the inherent benefit of this approach is the level of data characteristics it presents, as the qualitative nature of a job announcement necessitates that prospective employers use a constrained space to present the skills they are seeking in candidates. The content analysis of job announcement makes it possible to collect a large data base of consistent information in a relatively short period and at minimal expense.

Moallem (1995) conducted a content analysis study to analyze current job announcements in the field of instructional design and technology. The study generated descriptive information that describes the necessary skills and areas of knowledge associated with graduates of instructional design and technology programs. The study examined 150 job announcements that were gathered over three years. The content analysis results were reviewed and categorized to represent the organizations or institutions that advertised the positions. Findings from the study show that job requirements for graduates with master's degrees differ from those with doctoral degrees. There is the expectation that IDT graduates with master's degrees will be knowledgeable about project management and instructional design and development, while holders of doctoral degree are expected to have experience in teaching, conducting research, and writing grants, in addition to maintaining proficiency in instructional design and development. All recipients of graduate degrees are expected to be knowledgeable about computer technology and multimedia production (Moallem, 1995). The results also suggest that while the area of focus for the IDT programs seem to be in instructional design and development, additional electives and internships may be necessary to meet the needs of students with different career interests.

Kang and Ritzhaupt (2015) conducted a job announcement analysis of educational technology professional positions to identify the sought knowledge, skills, and abilities. The study involved a systematic process of collection, documentation, and analysis of 400 job announcements collected from different online job databases for more than five months. Over 150 knowledge, skill, and ability terms were found in those job 
announcements. The results of the study strongly demonstrate that in their roles, IDTs are expected to work in a variety of settings with multiple constituents/stakeholders.

A study designed by Ritzhaupt et al. (2018) identified competencies of educational technology professionals in the field. The four phases of the study included analysis of $400 \mathrm{job}$ announcement postings from five relevant databases. The study identified 176 knowledge, skill, and ability (KSA) competencies from the process, which were organized into KSA statements. The findings reported competencies such as instructional design, project management, learning theories, teamwork with diverse stakeholders, and 21st century technology proficiencies.

Klein and Kelly (2018) conducted a job announcement analysis of 393 job announcements collected from www.simplyhired.com and www.Indeed.com. Following the analysis, they interviewed 20 project managers. From the findings they reported that half of the employers in industry preferred four competencies of IDTs: using e-learning authoring software, effective collaboration, needs analysis, and the foundation of learning theories and principles.

Wang et al. (2021) conducted a study that utilized qualitative and quantitative methodologies to examine job announcements and identify core professional competencies for instructional designers. The researchers collected 1870 job announcements removed 840 incomplete or duplicate entries and used the remaining $1030 \mathrm{job}$ announcements for the study. Essential competencies were found to include soft skills (e.g., a capacity to work with different stakeholders), and technical competencies (e.g., working knowledge of video and audio production). The study presents a glimpse of current knowledge, skills, and abilities of instructional designers in different work contexts.

Employers' expectations regarding the roles and competencies of IDTs were identified in these studies: An ability to stay abreast of developments in learning theories (Ritzhaupt et al., 2010; Ritzhaupt \& Martin, 2014). Project management capabilities (Ritzhaupt \& Kumar 2015; Ritzhaupt \& Martin 2014; Williams van Rooij 2013). Proficiency with technologies, multimedia tools, and learning management systems (Ritzhaupt et al. 2010; Ritzhaupt \& Kumar 2015; Ritzhaupt \& Martin 2014; Sugar et al., 2012). Working knowledge of instructional design models and processes (Kang \& Ritzhaupt 2015; Klein \& Kelly, 2018; Ritzhaupt et al. 2010; Ritzhaupt \& Martin, 2014). ATD Research (2015) added that strong communication and collaboration skills the ability to "think analytically" are essential IDT skills.

\section{Defining Roles and Competencies of IDTs}

Computer-based technology has had a strong and continuing influence on instructional design, social media, mobile learning, online learning, assessment of learning, big data, and analytics. The integration of technologies and pedagogies has changed how teaching and learning has been reshaped to meet the varied needs and preferences of students, many of whom are considered digital natives. Higher education embraced technology in face-to-face classroom teaching, which became widely used in online learning in the 1990s (Chao et al., 2010; Halupa, 2019; Kumar \& Ritzhaupt, 2017). There has been a resurgence of interest in the constructivist theory because of its perceived compatibility with emerging technologies (Dawson et al., 2008; Gilakjani et al., 2013). These trends have affected the increase in employment of IDTs and also resulted in changes in their roles and competencies. The benefit of the studies that track IDT competencies and skills is in its ability to inform IDT programs on the preparation of students and enables students to exercise options related to employment opportunities.

According to Beirne and Romanoski (2018), the roles of most IDTs fall within four categories: designing, managing, training, and support. They add that the defined roles of IDTs may vary between institutions and among academic departments and offices within the same institution. These variations are evident in higher education and corporate position (job opening) announcements.

IDTs work in all sectors of the economy including education, industry, business, corporate, government, and non-profit organizations. Most work in business and industry, followed by higher education, consulting, and health care (Klein \& Kelly, 2018). Klein and Kelly (2018) identified five primary skills for IDTs: instructional 
design, instructional technology, communication and interpersonal skills, management, and personal skills. Some researchers suggest that different work experiences and environments influence the competencies of IDTs (Hoard et al., 2019). Notably, IDTs who work in corporate, government and non-profit environments require different competencies from those who work in education settings (Klein \& Jun, 2014; Ritzhaupt \& Kumar, 2015; Wang et al., 2021). Sugar et al. (2011) argues that the organizational culture in corporate settings differs fundamentally from the culture of college and university environments, and those settings generate ambiguities in the roles and expectations of IDT professionals (Berrett, 2016).

Halupa's (2019) study to identify the roles of IDTs and faculty members in online course development found that when expectations were not clearly delineated, IDTs experienced conflicts and lack of respect by faculty. Halupa suggests that to mediate the conflict or avoid it entirely, the roles of IDTs and faculty members should be collaborative, defined unambiguously as a partnership, and documented in institutional policy and procedures statements. In their study to identify the essential multimedia production knowledge and skills of IDT professionals who work in higher education, Sugar et al. (2011) found that it is important for IDT professionals to communicate to faculty or other development partners the extent of their multimedia production skills and how those skills will be applied to a project.

Raynis's (2018) content analysis study of 93 announcements for instructional design jobs documented the key responsibilities and qualifications of IDTs in corporate, government/military, health, higher education, and non-profit organizations. As in similar studies, the majority of the position announcements came from higher education, corporate, and healthcare sectors. Corporate setting positions were found to offer a wider range of responsibilities and qualifications than higher education and health industries where the need for specific expertise was more common. Apart from the widely recognized IDT "design and development" and "assessment and evaluation" skills, corporations were seeking project management, communication, collaboration, and technical skills (Kang \& Ritzhaupt, 2015; Raynis, 2016).

In an effort to understand how IDTs gained employment with institutions, Moskal (2012) studied higher education environments to document the employment and academic backgrounds of IDTs and the qualifications and expectations stated by their supervisors. An assumption was that understanding how IDTs function in higher education would advance their roles in the support of teaching and learning experiences of faculty and students. What emerged from Moskal's study were five qualities beyond IDT program preparation that were sought by higher education employers: flexibility, moral purpose, relationship building, time and project management, and ongoing professional development. IDTs were encouraged to go beyond designing instructional experiences to become leaders who could have an instantaneous and empowering effect on the future of higher education institutions seeking to redefine teaching and learning, distance education, and other support areas.

In their 2018 white paper, Beirne and Romanoski explored the reasons for a growing demand for IDTs: Who is filling the IDT roles? What are their responsibilities? How do they face the challenges of their work? With the realization that there is no defined pathway to a career in IDT, the authors reported that standardization, in addition to degree and certificate programs, will facilitate entry into the profession. Emerging developments, they argue, are vital to creating a rich vision of the IDT field. They surmise that the work of IDTs will be more clearly defined as the field grows.

A survey of IDTs to learn the backgrounds, qualifications, and employment histories of instructional designers who work in higher education in the U.S. was conducted by Intentional Futures in 2016. That survey found that IDTs tend to hold advanced degrees and have a wide range of work experience:

- $87 \%$ of respondents had masters' degrees, and $32 \%$ had doctoral degrees.

- $57 \%$ had 3 to $11+$ years of work experience in higher education.

- $53 \%$ had 3 to $11+$ years of experience in technology development.

- $53 \%$ had 3 to $11+$ years of experience in academic research roles. 
- $42 \%$ had 3 to $11+$ years of experience in graphic design.

The study revealed that despite the growing importance of IDTs in higher education, there remains some uncertainty about their specific roles.

Position announcements for IDTs generally seek individuals who will perform the traditional roles of instructional designers, but as expectations of expertise with an assortment of computer technologies have increased, the roles and responsibilities of IDTs have expanded non-technology competencies to include collaborative skills to authenticate their extensive work with faculty, content experts, and colleagues.

Though previous studies have focused on different aspects of IDTs' employment, responsibilities, competencies, and places of employment, there has been limited focus on their years of work experience, academic program preparation, academic degrees, compensation and position titles. This paper reports the findings of a study of position announcements by higher education institutions and corporate organizations offering employment opportunities to IDTs. The study results fill an information gap created by the constant and rapid changes in the field, changes in IDTs roles and responsibilities, and IDT hiring trends.

\section{METHODOLOGY}

\section{Data Collection}

A content analysis was done of 250 position announcements for instructional designers and instructional technologists posted on the popular online job search engine Indeed.com between March and June of 2019. Indeed.com was chosen as it is regarded as one of the topmost job sites in the world with the highest traffic and widest range of employer types. The Indeed.com employment search engine aggregates job listings from multiple sources: job boards, staffing firms' listings, and organizations' career websites. In a study that scrutinized postings from different search engines including Indeed.com, Raynis (2018) reported that 53.9\% of posted jobs were found on Indeed, more than any other job search engine.

Because job search boards such as Indeed.com collect job postings from different platforms and databases, they are a rich source of data on IDT position announcements. Job postings are succinct, accurate descriptions of the employers' expectations of potential applicants (Rios et al., 2020). The quantity of listings found in Indeed.com and information it provides in the job advertisements make it one of the most used job sites and a good source of data for this study.

For this study, the 250 announcements found on the Indeed.com website were selected after an initial screening that removed duplicates, positions not related to instructional designer and instructional technologist skills, and those that provided sketchy and incomplete information. Of those 250 postings, 125 announcements were derived from postings for instructional designers and 125 from postings for instructional technologists. The search terms for instructional designers and instructional technologists generated not only many job announcements, but other job titles for positions that matched their qualifications and competencies.

Content analysis provided a suitable method for analyzing the position announcements by providing the framework for coding words, word-phrase groups, themes, phrases, characters, or sentences within the position announcements. Content analysis supports interpretation of explicit and non-explicit texts (Babbie, 2010; Graneheim \& Lundman, 2004) and was deemed a good fit for this study as it expedited the conversion of textual, qualitative data into the quantitative data used in the analyses.

The content analysis of the announcements for instructional designer and instructional technologist positions in higher education and corporate settings in the United States followed a six-step process: (1) collection of position announcements from Indeed.com; (2) reviewing the announcements to remove duplicates and irrelevant posts (e.g., positions not related to instructional designer and instructional technologist positions); (3) develop categories for the identification of data and classification; (4) create code sets for the qualitative data; (5) code and combine the qualitative and descriptive data (e.g., words, word-phrase groups, themes, 
Table 1. Which organizations are hiring IDTs?

\begin{tabular}{lcc}
\hline Field & Frequency & Percentage \\
\hline Higher Education & 137 & $54.8 \%$ \\
Corporate & 113 & $45.2 \%$ \\
\hline
\end{tabular}

phrases, characters, or sentences found in the postings); and (6) conduct the required analysis to answer the research questions.

The printed announcements were sorted and manually inputted into an Excel spreadsheet that captured details related to the posted jobs: position title, industry, required degree, education field, skills, work experience, and salary offerings, all variables derived from the announcements themselves. The items in the Excel spreadsheet were reviewed, the data coded, and a preliminary analysis was conducted.

\section{Data Analysis}

The initial manual coding and preliminary analysis of the 250 announcements generated data that was reviewed and verified by the lead researcher. The process of review and rechecking was necessary by the sole researcher to ensure thoroughness and to establish reliability and the validity of the results. The emergent coding scheme espoused by Glaser and Strauss (2017) and constant comparative analysis strategies were used to assure consistency. The data generated from the announcements were collated and inspected to assure that they contained full job descriptions, including the skills and competencies sought by employers (Bengtsson, 2016).

\section{Limitations of the Study}

Serious attempts were made to capture all instructional designer and instructional technologist position announcements, but despite exhaustive searches it is possible that some announcements could have been missed.

There was no effort to compare the variables as they were manifested in higher education institutions versus corporate settings. Specific details about the hiring units or offices of employment were not examined. The findings do not readily offer explanations of the intentions of the prospective employers. No attempt was made to discern why and how institutions or businesses determined the personal characteristics or qualifications of suitable candidates.

It is not known if the writers of the job announcements were familiar with the preparation, roles, and competencies of IDTs.

\section{RESEARCH QUESTIONS AND FINDINGS}

This study was designed to create a clearer picture of the employment opportunities for IDTs and the performance expectations of higher education and corporate employers. These questions provided a framework for an analysis of position announcements for IDTs:

Which organizations are hiring IDTs?

What are the job titles found in the advertised IDT positions?

What academic programs prepared IDTs for advertised positions?

What academic degrees were sought for the advertised IDT positions?

What IDT experience and skills were identified in the advertised IDT positions?

How many years of IDT experience were sought in the advertised IDT positions?

What salary compensation information was included in the advertised IDT positions? 
Table 2. What are the job titles found in the advertised IDT positions?

\begin{tabular}{lcc}
\hline Field & Frequency & Percentage \\
\hline Instructional/Learning /Learning Experience Designer & 147 & $58.8 \%$ \\
Instructional Designer & 132 & $52.8 \%$ \\
Instructional/Learning/and Educational Technology & 90 & $36.0 \%$ \\
Instructional Technologist & 69 & $27.6 \%$ \\
Educational Technologist & 13 & $5.2 \%$ \\
Learning Experience Designer & 11 & $4.4 \%$ \\
Learning Technologist & 8 & $3.20 \%$ \\
Instructional Systems Designer & 4 & $1.6 \%$ \\
Director of Instructional Design & 3 & $1.2 \%$ \\
\hline
\end{tabular}

Table 3. What academic programs prepared IDTs for advertised positions?

\begin{tabular}{lcc}
\hline Field of study & Frequency & Percentage \\
\hline Instructional Technology \& Educational Technology & 99 & $39.6 \%$ \\
Instructional Design & 96 & $38.4 \%$ \\
Instructional technology & 53 & $21.2 \%$ \\
Education & 51 & $20.4 \%$ \\
Educational technology & 46 & $18.4 \%$ \\
Adult education/learning & 15 & $6.0 \%$ \\
Curriculum design/instruction & 13 & $5.2 \%$ \\
Media production/multimedia & 13 & $5.2 \%$ \\
Information technology & 12 & $4.8 \%$ \\
Communication & 12 & $4.8 \%$ \\
Computer science & 12 & $4.8 \%$ \\
Business & 6 & $2.4 \%$ \\
Technology & 5 & $2.0 \%$ \\
Organizational development & $5 \%$ \\
Instructional systems design & 4 & $1.6 \%$ \\
Educational design & 3 & $1.2 \%$ \\
Graphic design & 2 & $0.8 \%$ \\
Learning sciences/design & 2 & $0.8 \%$
\end{tabular}

\section{Which Organizations are Hiring IDTs?}

Of the 250 position announcements, the majority - $137(54.8 \%)$ - came from higher education and 113 (45.2\%) from corporate entities.

The data show that no fewer than nine job titles were associated with these announcements. Some variation of Instructional Designer, (including, Learning Designer, and Learning Experience Designer) was found 147 times (58.8\%) and Instructional Designer was found 132 times (52.8\%). Director of Instructional Design was mentioned only three times (1.2\%).

\section{What Academic Programs Prepared IDTs for Advertised Positions?}

Table 3 shows that the most frequently listed academic degrees were Instructional Technology and Educational Technology (99/39.6\%), Instructional Design (96/38.4\%), Instructional Technology (53/21.2\%), Education (51/20.4\%), and Educational Technology (46/18.4\%). Applicants from other academic fields were mentioned far less often, several as few as two times. 
Table 4. What academic degrees were sought for the advertised IDT positions?

\begin{tabular}{lcc}
\hline Field & Frequency & Percentage \\
\hline Bachelor's Degree & 167 & $66.8 \%$ \\
Master's Degree/Advanced degree & 91 & $36.4 \%$ \\
Master's Degree & 87 & $34.8 \%$ \\
Associate degree & 6 & 2.4 \\
Doctorate & 3 & 1.20 \\
High School Diploma or GED & 1 & 0.45 \\
\hline
\end{tabular}

\section{What Academic Degrees were Sought for the Advertised IDT Positions?}

Applicants with bachelor's degrees were requested in 167 (66.8\%) announcements, significantly more are those that required applicants with master's (87/34.8\%) or advanced degrees (91/36.4\%). Of those postings that required at minimum a bachelor's degree, some stated that master's degrees were "preferred." Postings that invited applications from candidates with an advanced degree did not specify either master's, postmaster's, or doctoral degrees. Doctorate/terminal degrees and high school diplomas were requested in fewer than $2 \%$ of announcements. Some announcements stated only possession of a graduate degree or college degree.

\section{What IDT Experience and Skills were Identified in the Advertised IDT Positions?}

Content analysis of the announcements revealed a wide range of preferred experiences and skills. Oral and written communication skills appeared 93 times (37.2\%). Competence with the Microsoft Office Suite was a somewhat distant second with 53 mentions (21.2\%). Other skill sets ranged from the highly technical, e.g.,

Table 5. What IDT experience and skills were identified in the advertised IDT positions?

\begin{tabular}{|c|c|c|}
\hline Field & Frequency & Percentage \\
\hline Communication/Oral and Written Skills & 93 & $37.2 \%$ \\
\hline Microsoft Office Suite & 53 & $21.2 \%$ \\
\hline Learning Management System & 51 & $20.4 \%$ \\
\hline Organizational Skills & 45 & $18.0 \%$ \\
\hline Multimedia/Media/AV & 45 & $18.0 \%$ \\
\hline Project Management & 33 & $13.2 \%$ \\
\hline Interpersonal Skills & 31 & $12.4 \%$ \\
\hline Technology skills & 28 & $11.2 \%$ \\
\hline Website development/Resource Management & 28 & $11.2 \%$ \\
\hline Instructional design & 25 & $10.0 \%$ \\
\hline Problem Solving & 25 & $10.0 \%$ \\
\hline Training & 22 & $8.8 \%$ \\
\hline Visual/Graphic Design Skills & 19 & $7.6 \%$ \\
\hline Adobe Creative Suite & 18 & $7.17 \%$ \\
\hline Computers & 16 & $6.4 \%$ \\
\hline E-Learning & 15 & $6.0 \%$ \\
\hline Presentation Skills & 14 & $5.6 \%$ \\
\hline Detail Oriented & 13 & $5.2 \%$ \\
\hline Time Management & 13 & $5.2 \%$ \\
\hline Analytical Skills & 12 & $4.8 \%$ \\
\hline Adult Education/Learning Theories & 12 & $4.8 \%$ \\
\hline Instructional Technology & 11 & $4.4 \%$ \\
\hline Collaborative Skills & 11 & $4.4 \%$ \\
\hline Teaching & 11 & $4.4 \%$ \\
\hline Technical Writing/Documentation & 10 & $4.0 \%$ \\
\hline Educational Technology & 10 & $4.0 \%$ \\
\hline Online Learning & 7 & $2.8 \%$ \\
\hline Quality Assurance & 7 & $2.8 \%$ \\
\hline Multi-tasking Skills & 6 & $2.4 \%$ \\
\hline
\end{tabular}


Table 5 (continued). What IDT experience and skills were identified in the advertised IDT positions?

\begin{tabular}{lcc}
\hline Field & Frequency & Percentage \\
\hline Learning Objects & 6 & $2.4 \%$ \\
Learning Technology & 6 & $2.4 \%$ \\
Curriculum & 6 & $2.4 \%$ \\
Distance Education/Learning & 6 & $2.4 \%$ \\
Accessibility/Assistive & 5 & $2.0 \%$ \\
Academic Technology & 3 & $1.2 \%$ \\
Ability to Negotiate & 3 & $1.2 \%$ \\
\hline
\end{tabular}

Table 6. How many years of IDT experience were sought in the advertised IDT positions?

\begin{tabular}{lcc}
\hline Field & Frequency & Percentage \\
\hline 3 to 5 years & 105 & $42.0 \%$ \\
1 - 3 years & 77 & $30.8 \%$ \\
7 to 10 years & 10 & $4.0 \%$ \\
5 to 7 years & 9 & $3.6 \%$ \\
10 years or more & 3 & $1.2 \%$ \\
\hline
\end{tabular}

28/11.2\% mentions of both Technology Skills and Website Development/ Resource Management, to the social or relational, e.g., Collaborative Skills (11/4.4\%), Multitasking Skills (6/2.4\%), Ability to Negotiate (3/1.2\%).

In higher education, hiring units sought applicants with skills in adult/continuing education, instructional/educational technology, online/e-learning, extended learning, information technology, distance education, and other academic departments.

The responsibilities documented by this study appear to be consistent with those described by Beirne and Romanoski (2018), and Intentional Futures (2016).

\section{How Many Years of IDT Experience were in the Advertised IDT Positions?}

Almost half (42\%) of announcements included a requirement of 3 to 5 years of experience; 1 to 3 years was second with 77 mentions (30.8\%). Only 3 mentions (1.2\%) were found for 10 or more years of experience.

\section{What Salary Compensation Information was Included in the Advertised IDT Positions?}

Few of the 250 position announcements for IDTs included a specific salary. Seven postings had the familiar "commensurate with experience;" others stated per-hour or monthly pay rates. Some compensation was described as "Pay Grade" - a figure known to HR personnel. Of the annual salary ranges included in many of the announcements, the most frequent was $\$ 50,000$ to $\$ 85,000$ - a figure consistent with entry- to middlelevel positions in the field. Five postings had salary ranges that exceeded $\$ 100,000$.

Table 7. What salary compensation information was included in the advertised IDT positions?

\begin{tabular}{lcc}
\hline Field & Frequency & Percentages \\
\hline Per Hour Rates & & \\
$\quad \$ 69.00$ & 3 & $1.2 \%$ \\
$\$ 13.00-15.00$ & 1 & $0.45 \%$ \\
$\$ 24.38-\$ 33.52$ & 1 & $0.45 \%$ \\
\hline Per Month Rates & & \\
$\$ 3,470-\$ 3,979$ & 1 & $0.45 \%$ \\
$\$ 3470-\$ 6486$ & 1 & $0.45 \%$ \\
\hline Pay Grade & 3 & $1.2 \%$ \\
\hline Commensurate with Experience & 7 & $2.8 \%$ \\
\hline
\end{tabular}


Table 7 (continued). What salary compensation information was included in the advertised IDT positions?

Annual/Per Year Salary Ranges Found

$\$ 110,000$ per year

$\$ 92,700-\$ 126,900$

$81,548-\$ 151,852$

$\$ 87,412$ - $\$ 111,565$

$\$ 80,248-\$ 116,328$

$\$ 75,000-\$ 85,000$

$\$ 74,000-\$ 75,000$

$\$ 67,000$ - $\$ 77,000$

$\$ 65,000-\$ 85,000$

$\$ 65,000-\$ 85,000$

$\$ 65,000$ - $\$ 68,000$

$\$ 62,000$ - \$93,000

$\$ 60,000$ - $\$ 75,000$

$\$ 60,000$ - $\$ 70,000$

$\$ 55,000$ -

$\$ 54,900-\$ 75,500$

$\$ 54,900$ - \$75,500

$\$ 54,900$ - $\$ 75,500$

$\$ 52,575$ - $\$ 68,940$

$\$ 51,975$ - \$71,497

$\$ 50,000$ - $\$ 75,000$

$\$ 50,000-\$ 75,000$

$\$ 50.00-\$ 60.00$

$\$ 50,000-\$ 55,000$

$\$ 50,210$

$\$ 47,088-\$ 65,400$

$\$ 47,722$ - $\$ 55,477$

$\$ 45,000$

$\$ 44,167$

$\$ 42,758$

$\$ 42,000$

$\$ 40,500$ - \$56,000

$\$ 40,000-\$ 50,000$

$\$ 40,000-\$ 45,000$

$\$ 36,072-\$ 55,000$

$\$ 34,151-\$ 37,318$

\section{DISCUSSION}

This study confirms the interest in instructional designers and technologists by higher education institutions and business organizations (Raynis, 2018; Sugar et al., 2011; Surry \& Robinson, 2001; Wang et al., 2021). The interest affirms recognition of the value of their roles to the creation of instructional materials and the delivery of instruction. This trend is consistent with O'Malley's (2017) observation that education, business, and industry administrators are recognizing that faculty and instructors need assistance in developing and teaching online courses.

\section{Job Titles}

IDT job titles are not limited to Instructional Designer or Instructional Technologist (Hoard et al., 2019; Raynis, 2018). The study's search was for instructional designers and instructional technologist, but other job titles emerged requiring the similar qualifications and competencies. As the field has evolved and more roles are delineated for IDTs, the list of titles has grown to include Educational Technologist, Learning Experience Designer, Learning Technologist, Learning Designer, and Instructional Systems Designer. The study by Raynis 
(2018) identified different titles that used for IDTs. Sharif and Cho (2015) observed that the profession is known by various titles and even in the same organization. In this study, the words, "Instructional" and "Designer" occurred in $78.5 \%$ and $83.9 \%$ of the job titles. While job titles suggest a difference in the jobs themselves, the roles and responsibilities are similar. Employers appear to pick position titles that best fit their needs, organizational structures, and levels of authority.

\section{Field of Academic Preparation}

The announcements sought candidates from different academic disciplines. This study found that Instructional Design and Educational Technology were the academic programs most frequently sought (99/39.6\%) in position announcements, choices reflected in a 2004 study conducted by Schwier, Campbell, and Kenny. Instructional Design was found almost as frequently (96/38.4\%), which seemed somewhat redundant on the same list with Instructional Design and Educational Technology programs. Further review of academic offerings found that some institutions with newer IDT programs have concentrations in Instructional Design. Other disciplines listed in the sought field of academic preparation for IDTs in the job announcements are Adult Education/Learning, Curriculum Design/Instruction, Media Production/Multimedia, Information Technology, and Communication.

\section{Academic Qualifications}

As noted in the findings of the study, bachelor's degrees were the predominant minimum academic degree requirements found in 167 (66.8\%) announcements, master's degrees in 87 (34.8\%), or advanced degrees (91/36.4\%). Of those postings that required a minimum of a bachelor's degree, some stated that master's degrees or advanced degrees were "preferred." The preference for graduate degrees seems consistent with the Intentional Futures (2016) report, which states that $87 \%$ of the Instructional Designer professionals in higher education held a master's degree; $32 \%$ held a Ph.D. or Ed.D., since the preference was for advanced degrees.

Some announcements sought candidates with an associate degree in IDT. This was surprising as IDT programs are not known to offer associates degrees.

Most of the IDT job postings found were placed by higher education institutions (137/54.8\%); corporate entities posted $113 / 45.2 \%$. This is consistent with the findings of Raynis (2018) who documented IDT job postings by higher education institutions, corporate entities, and the healthcare industry. Identifying specific types of higher education institutions and hiring units were not variables of this study. Similarly, the type of business organizations and the hiring departments were also not identified by the study. The International Board of Standards for Training, Performance, and Instruction (IBSTPI, 2012) posits that instructional designers make their entry into the field of IDT from different educational and technological backgrounds and that they work in various types of business, higher education, and K-12 education settings.

\section{Roles and Responsibilities}

As IDTs are expected to have a plethora of skills to function in their roles, those joining or changing jobs in the field are equally expected to demonstrate to potential employers a working knowledge of a variety of competencies (Ritzhaupt \& Martin, 2014). Some researchers find that different work environments influence the competencies of IDTs (Hoard et al., 2019; Klein \& Jun, 2014; Ritzhaupt \& Kumar, 2015). IDTs who work in corporate, government, and non-profit environments are expected to demonstrate different competencies from those who work in the education field (Klein \& Jun, 2014; Ritzhaupt \& Kumar, 2015; Wang et al., 2021). Sugar et al. (2011) found distinguishable differences between IDT practices in higher education and corporate entities, namely that the attention of instructional designers who work in higher education institutions is focused on identifying alternative solutions for delivery of academic coursework, while instructional designers in corporate settings focus on staff training and are more customer oriented. This distinction raises an important question: Why are IDT academic programs not designating specializations that will prepare students specifically for the corporate environment, just as some programs prepare their graduates for the $\mathrm{K}-12$ environment? The demand for their skills in higher education institutions is on the increase. There is 
growing interest in higher education for IDTs as they fill roles that help in preparing and supporting faculty in online teaching, course development and improvement, integration of technology and pedagogy, and the application of the instructional design models (Bickerstaff \& Cormier, 2015; Chiasson et al., 2015; Elliott et al., 2015; Intentional Futures, 2016). The peculiar nature of working with faculty and the dynamics of higher education institutions may require preparing IDTs for higher education.

The wide variety of job-related experience and skills sought in the job announcements suggests that IDT professionals wear different hats as they support or manage various projects. Dynamic work environments, advancements in learning and teaching technology applications, and demands for individualized instructional methods underscore the need for strong communication skills, a quality at the top of the list of required skills found in the position announcements. IDTs are expected to interact with subject matter experts and collaborate with others in their work unit and throughout their organization (ATD Research, 2015). The importance of strong communication skills for IDTs has been identified consistently by researchers (Halupa, 2019; IBSTPI, 2012; Kenny et al., 2005; Klein \& Kelly, 2018; Raynis, 2018; Sugar et al., 2011; Sugar et al., 2012; Xu \& Morris, 2007).

Problem-solving and instructional design skills were each mentioned in 25 (10\%) of announcements. Solving ill-defined instructional problems, recommending appropriate interventions, and making decisions in complex environments populated by faculty or content experts with varying expectations should be anticipated by IDTs (Ertmer \& Stepich, 2005; Gray et al., 2015; Kenny et al., 2005). Irlbeck (2011) encourages the development of effective problem-solving skills in the preparation of IDT professionals.

Project management was identified $33(13.2 \%)$ times in the announcements. This IDT skill was also found to be important in studies by Kenny et al. (2005), Intentional Futures (2016), Kang and Ritzhaupt (2015), and Raynis (2018).

The competencies expected of IDTs in educational settings include effective collaboration skills, knowledge of learning theories and principles, effective communication skills, experience in e-learning technologies, the ability to use learning management systems, and knowledge of the instructional design models (Klein \& Kelly, 2018). Similarly, Ritzhaupt and Kumar (2015) noted that the competencies that are essential for IDT professionals in higher education are instructional design and learning theory, soft skills and technical skills, willingness to learn on the job, and capacity to adjust to evolving technologies and processes.

It is not surprising that regardless of the type of workplace, IDTs will work with technology. This study found that $84.4 \%$ of the postings sought candidates with a broad range of technological skills. The Intentional Futures (2016) survey of instructional designers in higher education found that $82.29 \%$ ranked "learning new technologies" as particularly important. This is consistent with previously reported expectations for IDTs (Irlbeck, 2011; Intentional Futures, 2016; Miller \& Stein, 2016; Raynis, 2018).

\section{Compensation}

Few of the announcements included salary compensation for the advertised positions and those that did showed substantial disparity. It can be a factor of the type of hiring organization; position title (an indicator of level of responsibilities); location, budgetary constraints, and academic qualifications; work experience; and the value placed on the contributions of the position.

One to five years of experience was found most frequently in the advertised positions. New graduates of IDT academic programs might find that internships or meaningful volunteer experience will prepare them to qualify for some positions. Quite naturally, those with more years of experience will be attracted to senior level IDT or director positions that offer more authority and higher compensation.

There are similarities in the IDT job descriptions placed by higher education institutions and corporate entities. All employers are seeking college graduates with traditional IDT skills and experiences and good communication skills. A careful look at the position announcements raises the question about who writes the IDT job descriptions or position announcements, as some position announcements included competencies that were not consistent with the required academic backgrounds. Is it the hiring department, 
human resources staff, members of the search committee, or an accepted campus expert? Of the 250 position announcements included in this study, some seem to be near copies from other postings. That in itself is outside the scope of this paper. The question is, do the job descriptions reflect the IDT skills and competencies required to meet the needs of the position as well as the hiring unit and organization? When a position announcement seeks candidates whose academic degrees or programs are not a close match with IDT competencies, it becomes doubtful if suitable applicants will be attracted to the job. For example, an announcement that describes the competencies of an instructional designer but asks for a degree in computer science is an unlikely match, unless an applicant with a computer science degree learned the required skills through previous work experience. Writers of announcements for IDT positions must be familiar with essential IDT skills and competencies if applicants can be found who will meet the expectations of the hiring organizations.

\section{IMPLICATIONS}

\section{Identity of IDTs}

Formal preparation in an IDT academic program is a widely accepted credential for entry into the field as this study suggests and there are expected competencies that are the byproducts of such programs for new graduates seeking employment. However, some have been accepted into the role of IDT who have degrees from other fields and with no substantial related work experience or competence. In the analysis of position announcements, there were postings that were open to graduates of other academic disciplines. IDT position announcements that indicate interest in individuals who do not come from IDT academic programs create confusion as they draw applicants from multiple fields. Some IDTs venture into the field from other disciplines (Mancilla \& Frey, 2020). Following their study Beirne and Romanoski (2018) also confirmed that there are individuals who enter the IDT profession from different fields due to the multiple unregulated paths to a career as an IDT professional. They argue for standardization for entry into the profession. Intentional Futures (2016), notes that using various qualifications to accept IDT jobs leads to the lingering ambiguity about the unique qualifications of IDTs. The increase in hiring opportunities for IDTs calls for better positioning of the field and the practitioners in order to correct any identity problems, offer recognition of who is an appropriately trained instructional designer or instructional technologist, and their worth vis-à-vis their contributions to the workplace (Wunsch, 2000). Schwier and Wilson report that some instructional designers believe that "their position is neither understood nor respected" (2010, p.141), a sentiment previously echoed by Wunsch (2000). Part of the identity problem has been created or exacerbated by the fact that there are different pathways through which practitioners join the profession and there are no professional regulations (Schwier et al., 2004). Participants in a study by Schwier et al. (2004) commented that IDTs struggle with identity and image problems and lack respect on the job. One respondent in their study put it succinctly:

My experience is not typical instructional designer experience. ...Up until the last months I was at [an institution of higher education], I was the only instructional designer who had a teaching background. The others had come through a whole series of routes to being instructional designers. I was working with a physicist, a classicist, a creative writer, a television producer, a mathematician and, oh yes, there was one other person with a teaching background (2004, p. 77).

The identity issue could suggest a lack of regulated entry standards and active representative body such as has been established for librarians, for example, it is almost impossible to hire a librarian without a masters' degree from an ALA accredited institution.

Improving the recognition of the value of IDTs and ameliorating the disquiet about their identity and credentials may depend on the hiring organizations' decisions to describe job titles, responsibilities, and work environments with precise role definitions and delineations. Provision of market-driven compensation will establish an organizational culture that acknowledges the value and perception of IDTs as practitioners and professionals. Acknowledging that their role may be misunderstood, IDTs need to be prepared to provide 
convincing responses to employers and colleagues regarding any doubts about their efficacy, contributions, and bottom-line value of their work. As Schwier and Wilson (2010) surmised, "to promote or raise the profile of IDTs, practitioners are required to educate colleagues about the practices and contributions of instructional design" (p. 141).

\section{Professional Development}

While the study did not focus on professional development, but is it necessary that as the field of IDT is constantly evolving, IDT practitioners need to be prepared to advance with a profession whose access to and use of new technologies enhances teaching and learning opportunities. Schwier et al. (2004) suggest that professional organizations have an important role to play. Ritzhaupt et al. (2020) state that professional associations exist to support professionals in different fields to enable the members to continue in their professional development. While the costs involved in professional development (e.g., membership fees and travel) may be a factor, there are also some free or less-expensive options (e.g., free Webinars, journals, streamed conference presentations, regional or local conferences). Since professional associations are volunteer organizations, the time and resources they can apportion to their members is limited (Ritzhaupt et al., 2020).

The fact that IDTs are being sought and institutions are offering academic programs in IDT are signs that the future is bright for the profession. It may also signal that it is time for the field to be better regulated to assure increased recognition, minimized ambiguity, and premium performance.

\section{Preparation of IDTs}

Part of the benefit of the studies that examine the role and competencies of IDT professionals is to equip academic programs with empirical evidence about the skills their students will need to meet the demands of the marketplace. Higher education institutions that offer IDT programs need to prepare their students for multiple work environments. Graduates may find employment in K-12 to higher education institutions, business, industry, government, or military settings. As the results of this and other studies suggest, IDT academic programs that have focused strictly on education-based careers would do well to add a corporatetrack IDT curriculum that includes classes in workforce development, performance improvement, project management, communications, and problem-solving. Preparing students for specific industries may be difficult to implement by academic programs, but the importance of context in the practice of IDT and the need for relevant real-life experiences needs to be recognized. A graduate level program should prepare IDTs to take on roles as professionals who can design, manage, supervise, and inspire (Kim et al., 2008).

\section{CONCLUSION}

The relatively long history and practice of instructional design, along with technological and societal developments, have led to the increased demand for instructional designers and instructional technologists to work in higher education and in corporate settings. The myriads of required experiences and expectations as expressed in the position announcements suggest that IDTs need to be well prepared to tackle a variety of roles in different organizational contexts. Well-rounded academic preparation enables IDTs to succeed in the workplace, engaging with content- or subject-matter experts in corporate settings and collaborating with faculty in higher education to integrate technologies into their teaching, leading with online course development, and offering support in the selection and application of appropriate pedagogies to support teaching and learning. Academic programs that prepare students to pursue work environments outside of higher education will equip graduates with skills to develop training and development programs and create instructional materials. As more IDTs engage in higher education and corporate work settings, faculty and content experts will become more familiar with their contributions and see the benefit of working with them as full partners to improve and deliver high quality teaching and learning endeavors. Organizations will need to establish a culture in which IDTs are seen as collaborators with unique skills working with subject matter experts to add value to their work. Well-written position announcements will pair IDT competencies with 
employer expectations - a match that will establish IDTs as having competencies that are not found elsewhere in the institution or organization.

As user capabilities and technological applications continue to expand across social and economic dimensions, the demand for people who can integrate technology with pedagogy, improve classroom instruction, and support online and distance learning efforts will also continue to grow. This demand calls for the support of professional associations and academic programs to continuously monitor the trends in emerging areas and incorporate them into a curriculum that equips IDTs to take on roles and responsibilities in the field, whether in education or corporate settings.

Funding: Author received no financial support for the research and/or authorship of this article.

Declaration of interest: Author declares no competing interest.

Data availability: Data generated or analysed during this study are available from the author on request.

\section{REFERENCES}

ATD Research, IACET, \& Rothwell and Associates. (2015). Skills, challenges, and trends in instructional design. ATD Research. https://www.iacet.org/default/assets/File/pdfs/2015\%20ATD_Research_Skills_ Challenges_and_Trends_in_Instructional_Design.pdf

Babbie, E. (2010). The practice of social research (12th ed.). Wadsorth.

Beirne, E., \& Romanoski, M. (2018). Instructional design in higher education: Defining an evolving field. Online Learning Consortium. https://olc-wordpress-assets.s3.amazonaws.com/uploads/2018/07/ Instructional-Design-in-Higher-Education-Defining-an-Evolving-Field.pdf

Bengtsson, M. (2016). How to plan and perform a qualitative study using content analysis. NursingPlus Open, 2, 8-14. https://doi.org/10.1016/j.npls.2016.01.001

Berrett, D. (2016, February 29). Instructional Design: Demand growth for a new breed of academic. The Chronicle of Higher Education. https://www.chronicle.com/article/Instructional-Design/235425

Bichelmeyer, B. A., Misanchuk, M., \& Malopinsky, L. (2001). Adapting a master's degree course to the web: A case analysis. Quarterly Review of Distance Education, 2(1), 49-58. https://www.learntechlib.org/p/90425/

Chao, I. T., Saj, T., \& Hamilton, D. (2010). Using collaborative course development to achieve online course quality standards. The International Review of Research in Open and Distributed Learning, 11(3), 106126. https://doi.org/10.19173/irrodl.v11i3.912

Christensen, T. K., \& Osguthorpe, R. T. (2004). How do instructional-design practitioners make instructionalstrategy decisions? Performance Improvement Quarterly, 17(3), 45-65. https://doi.org/10.1111/j.1937-8327.2004.tb00313.x

Cox, S., \& Osguthorpe, R. T. (2003). How do instructional design professionals spend their time? TechTrends, 47(3), 45-47. https://doi.org/10.1007/BF02763476

Da Silva, C. (2016). Transforming from instructional design to learning experience design. eLearning Industry. https://elearningindustry.com/learning-experience-design-what-need-know

Daniels, L., Sugar, W., Abbie, B., \& Hoard, B. (2012, March). Educational technology professionals in higher education: Multimedia production competencies identified from a Delphi study. In Society for Information Technology \& Teacher Education International Conference (pp. 1711-1714). Association for the Advancement of Computing in Education (AACE).

Dawson, K., Cavanaugh, C. \& Ritzhaupt, A. (2008). Florida's EETT Leveraging Laptops Initiative and its impact on teaching practices. Journal of Research on Technology in Education, 41(2), 143-159. https://doi.org/10.1080/15391523.2008.10782526 
Ertmer, P. A., \& Stepich, D. A. (2005). Instructional design expertise: How will we know it when we see it? Educational Technology,45(6), 38-43.

Gilakjani, A. P., Leong, L., \& Ismail, H. N. (2013). Teachers' use of technology and constructivism. International Journal of Modern Education and Computer Science, 4, 49-63. https://doi.org/10.5815/ijmecs.2013.04.07

Glaser, B., \& Strauss, A. (2017). The discovery of grounded theory: Strategies for qualitative research. Sociology Press. https://doi.org/10.4324/9780203793206

Graneheim, U. H., Lundman, B. (2004). Qualitative content analysis in nursing research: Concepts, procedures and measures to achieve trustworthiness. Nurse Education Today, 24(2), 105-112. https://doi.org/10.1016/j.nedt.2003.10.001

Gray, C. M., Dagli, C., Demiral-Uzan, M., Ergulec, F., Tan, V., Altuwaijri, A. A., \& Boling, E. (2015). Judgment and instructional design: How ID practitioners work in practice. Performance Improvement Quarterly, 28(3), 25-49. https://doi.org/10.1002/piq.21198

Halupa, C. (2019). Differentiation of roles: Instructional designers and faculty in the creation of online courses. International Journal of Higher Education, 8(1), 55. https://doi.org/10.5430/ijhe.v8n1p55

Hoard, B., Stefaniak, J., Baaki, J., \& Draper, D. (2019). The influence of multimedia development knowledge and workplace pressures on the design decisions of the instructional designer. Educational Technology Research and Development, 67(6), 1479-1505. https://doi.org/10.1007/s11423-019-09687-y

IBSTPI (International Board of Standards for Training). (2012). Instructional design competencies. https://www.scribd.com/document/240565112/IBSTPI-Competencies2012

Intentional Futures. (2016). Instructional design in higher education. https://intentionalfutures.com/work/instructional_design

Irby, T., \& Strong, R. (2015). Instructional competencies needed to develop instructional strategies for mobile learning in fields of agricultural education. The Quarterly Review of Distance Education, 16(3), 77-81.

Irlbeck, S. (2011). Educating for an instructional design and technology future. The Journal of Applied Instructional Design, 1(2), 19-23.

ISTE (2017). ISTE standards. https://www.iste.org/standards/standards

Kang, Y., \& Ritzhaupt, A. D. (2015). A job announcement analysis of educational technology professional positions: Knowledge, skills, and abilities. Journal of Educational Technology Systems, 43(3), 231-256. https://doi.org/10.1177/0047239515570572

Kenny, R. R., Zhang, Z., Schwier, R. A., \& Campbell, K. (2005). A review of what instructional designers do: Questions answered, and questions not asked. Canadian Journal of Learning and Technology, 31(1), 916. https://doi.org/10.21432/T2JW2P

Kilgore, W. (2016). UX to LX: The rise of learner experience design. EdSurge News. https://www.edsurge.com/news/2016-06-20-ux-to-lx-the-rise-of-learnerexperience-design

Kim, C., Lee, J., Merril, M., Spector, J., \& Van Merrienboer, J. (2008). Foundations for the Future. In J. Spector, M. Merrill, J. Van Merrienboer, \& M. Driscoll (Eds.), Handbook of research on educational communications and technology (3rd ed.) (pp. 807-815). Taylor \& Francis.

Kim, J. (2015). Instructional designers by the numbers. Inside Higher Ed. https://www.insidehighered.com/blogs/technology-and-learning/instructional-designers-numbers

Klein, J. D., \& Jun, S. (2014). Skills for instructional design professionals. Performance Improvement, 53(2), 41-46. https://doi.org/10.1002/pfi.21397

Klein, J. D., \& Kelly, W. Q. (2018). Competencies for instructional designers: A view from employers. Performance Improvement Quarterly, 31(3), 225-247. https://doi.org/10.1002/piq.21257 
Kumar, S., \& Ritzhaupt, A. (2017). What do instructional designers in higher education really do? International Journal on E-Learning, 16(4), 371-393.

Larson, M. B., \& Lockee, B. B. (2009). Preparing instructional designers for different career environments: A case study. Educational Technology Research Development, 57, 1-24. https://doi.org/10.1007/s11423006-9031-4

Litchfield, B. C. (2017). Instructional design in higher education. In R. A. Reiser \& J. V. Dempsey (Eds.), Trends and issues in instructional design and technology (pp. 185-191). Pearson.

Malamed, C. (2015). Instructional design needs a new name! elearning Coach. http://theelearningcoach.com/elearning_design/isd/new-name-for-id/

Mancilla, R. \& Frey, B. (2020). A model for developing instructional design professionals for higher education through apprenticeship: Blending theory and practice. The Journal of Applied Instructional Design, 9(2). https://doi.org/10.51869/92rmbf

Martin, F., \& Ritzhaupt, A. D. (2020). Standards and competencies: For instructional design and technology professionals. In J. K. McDonald \& R. E. West (Eds.), Design for learning: Principles, processes, and praxis (1st ed.). EdTech Books.

Miller, S., \& Stein. G. (2016). Finding our voice: Instructional designers in higher education. Educause Review. http://er.educause.edu/articles/2016/2/finding-our-voice-instructional-designers-in-highereducation

Moallem, M. (1995). Analysis of job announcements and required competencies for instructional technology professionals [Paper presentation]. American Educational Research Association Annual Meeting, San Francisco, CA. Retrieved from https://files.eric.ed.gov/fulltext/ED405355.pdf

Moskal, T. M. (2012). Instructional designers in higher education (Doctoral dissertation). https://digitalcommons.unl.edu/cehsedaddiss/121/

O'Malley, S. (2017). What do instructional designers do? Inside Higher Ed. https://www. insidehighered.com/digital-learning/article/2017/08/02/what-do-instructional-designers-do?

Raynis, M. (2018) Analysis of instructional design job announcements (2016). Current Issues in Emerging eLearning, 4(1), 9. https://scholarworks.umb.edu/ciee/vol4/iss1/9

Rios, J. A., Ling, G., Pugh, R., Becker, D., \& Bacall, A. (2020). Identifying critical 21st-century skills for workplace success: A content analysis of job advertisements. Educational Researcher, 49(2), 80-89. https://doi.org/10.3102/0013189X19890600

Ritzhaupt, A. D., \& Kumar, S. (2015). Knowledge and skills needed by instructional designers in higher education. Performance Improvement Quarterly, 28(3), 51-69. https://doi.org/10.1002/piq.21196

Ritzhaupt, A. D., \& Martin, F. (2014). Development and validation of the educational technologist multimedia competency survey. Educational Technology Research and Development, 62(1), 13-33. https://doi.org/10.1007/s11423-013-9325-2

Ritzhaupt, A. D., Martin, F., Pastore, R., \& Kang, Y. (2018). Development and validation of the educational technologist competencies survey (ETCS): Knowledge, skills, and abilities. Journal of Computing in Higher Education, 30(1), 3-33. https://doi.org/10.1007/s12528-017-9163-z

Ritzhaupt, A., Martin, F., \& Daniels, K. (2010). Multimedia competencies for an educational technologist: A survey of professionals and job announcement analysis. Journal of Educational Multimedia and Hypermedia, 19(4), 421-449.

Ritzhaupt, D., Stefaniak, J., Conklin, S., \& Budhrani, K. (2020). A Study on the Services Motivating Instructional Designers in Higher Education to Engage in Professional Associations. The Journal of Applied Instructional Design, 9(2), 27. https://doi.org/10.51869/adrjssckb 
Rowland, G. (1992). What do instructional designers actually do? An initial investigation of expert practice. Performance Improvement Quarterly, 5(2), 65-86. https://doi.org/10.1111/j.19378327.1992.tb00546.x

Rozitis, C. P. (2017). Instructional design competencies for online high school teachers modifying their own courses. TechTrends, 61(5), 428-437. https://doi.org/10.1007/s11528-017-0204-2

Schwier, R. A., \& Wilson, J. R. (2010). Unconventional roles and activities identified by instructional designers. Contemporary Educational Technology, 1(2), 134-147. https://doi.org/10.30935/cedtech/5970

Schwier, R. A., Campbell, K., \& Kenny, R. (2004). Instructional designers' observations about identity, communities of practice and change agency. Australasian Journal of Educational Technology, 20(1). https://doi.org/10.14742/ajet.1368

Sharif, A., \& Cho, S. (2015). 21st-Century instructional designers: Bridging the perceptual gaps between identity, practice, impact and professional development. International Journal of Educational Technology in Higher Education, 12(3), 72-85. https://doi.org/10.7238/rusc.v12i3.2176

Stefaniak, J., Baaki, J., Hoard, B., \& Stapleton, L. (2018). The influence of perceived constraints during needs assessment on design conjecture. Journal of Computing in Higher Education, 30(1), 55-71. https://doi.org/10.1007/s12528-018-9173-5

Sugar, W., Brown, A., \& Daniels, L. (2007). Media production curriculum and competencies: Identifying entrylevel multimedia production competencies and skills of instructional design and technology professionals: Results from a biennial survey [Paper presentation]. Association of Educational Communications and Technology, Anaheim, CA.

Sugar, W., Brown, A., Daniels, L., \& Hoard, B. (2011). Instructional design and technology professionals in higher education: Multimedia production knowledge and skills identified from a Delphi Study. The Journal of Applied Instructional Design, 1(2), 30-46.

Sugar, W., Hoard, B., Brown, A., \& Daniels, L. (2012). Identifying multimedia production competencies and skills of instructional design and technology professionals: An analysis of recent job postings. Journal of Educational Technology Systems, 40(3), 227-249. https://doi.org/10.2190/ET.40.3.b

Surry, D. W., \& Robinson, M. A. (2001). A taxonomy of instructional technology service positions in higher education. Innovations in Education and Teaching International, 38(3), 231-238. https://doi.org/10.1080/14703290110051406

Wang, X., Chen, Y., Ritzhaupt, A. D., \& Martin, F. (2021). Examining competencies for the instructional design professional: An exploratory job announcement analysis. International Journal of Training and Development. https://doi.org/10.1111/ijtd.12209

Williams van Rooij, S. (2013). The career path to instructional design project management: An expert perspective from the US professional services sector. International Journal of Training and Development, 17(1), 33-53. https://doi.org/10.1111/j.1468-2419.2012.00414.x

Wunsch, M. A. (2000). Killing the old myths: Positioning an instructional technology center for a new era in higher education. College and University Media Review, 7(1), 51-71.

$\mathrm{Xu}, \mathrm{H} .$, \& Morris, L. V. (2007). Collaborative course development for online courses. Innovation in Higher Education, 32, 35-47. https://doi.org/10.1007/s10755-006-9033-5

Correspondence: John Nworie, Independent Researcher, USA. E-mail: Jxn900@yahoo.com 